\title{
INVESTIGATION ON EFFECT OF MAGNETITE NANOFLUID ON PERFORMANCE AND EMISSION PATTERNS OF METHYL ESTERS OF BIO DIESEL
}

\author{
Yuvarajan $\mathrm{D}^{\mathrm{a}}$, Venkata Ramanan $\mathrm{M}^{\mathrm{b}}$ \\ ${ }^{a}$ Department of Mechanical Engineering, Jeppiaar Institute of Technology, Chennai, India \\ ${ }^{b}$ Department of Mechanical Engineering, College of Engineering, Anna University, Chennai, India
}

Submitted 26 Aug. 2015; accepted 12 Jan. 2016

\begin{abstract}
The objective of this work is to reduce viscosity and other related problems associated with biodiesel by adding non polluting additives. Magnetite is chosen as an additive in this work. Significant reason for using magnetite as an additive is that the magnetic nano particles (magnetite) can be collected from exhaust using magnetic billets in the tail pipe. Performance and emission test is carried out in single cylinder compression ignition engine using base and modified fuel and is compared to diesel. Modified fuel consists of $98.5 \%$ base fuel (Rice bran oil methyl ester), $1.3 \%$ additives (magnetite) and $0.2 \%$ surfactant (tri methyl ammonium hydroxide) by volume. The experimental work confirmed that by adding magnetite to methyl esters of rice bran oil enhances the brake thermal efficiency by $4.27 \%$ with $5.17 \%$ reduction in SFC. In addition, $10.8 \%, 9.1 \%$ and $8.49 \%$ reduction in HC, CO and NOx emissions is observed respectively.
\end{abstract}

Keywords: air-fuel ratio, delay period, ignition, performance.

\section{Introduction}

Vegetable oil is found to be a potential alternative fuel owing to its properties very similar to Diesel. Vegetable oil is used as an alternative fuel due to its inbuilt advantages. The significant aspects of considering vegetable oil as a potential alternative fuel is that, it can be used in modern diesel engines with no modifications. Vegetable oils are used as direct fuel or blended with diesel fuel in diesel engine. It also emits a lesser amount of carbon monoxide and hydrocarbon emissions. In spite of numerous advantages, it also emits higher percentage of nitric oxide (NOx) emission (Aydin, Bayindir 2010; Ramadhas et al. 2005). The possible reason reported is due to loss in engine power as it increases NOx emissions (Ryu 2010; Karabektas 2009). NOx emissions in diesel engine fuelled with biodiesel are reduced by adding nano particles in liquid form. Nano particles in liquid form reduce the $\mathrm{NO}_{\mathrm{x}}$ emissions as it acts as a catalyst and enhances the rate of combustion (Choi, Oh 2006). $\mathrm{NO}_{\mathrm{x}}$ emissions are significantly related to the temperature in the combustion chamber. It has been experimentally found that by adding nano particles in liquid state lowers the thermal loading, heat flux and combustion chamber surface temperature (Galfetti et al. 2007). Further, it has been experimentally found that the brake thermal efficiency of biodiesel is improved significantly with addition of nanofluid. Chemical compositions of fuel are altered with inclusion of nanofluid (Jung et al. 2005). In addition nano fluid releases energy when diffused into higher temperature. Enhancement in oxidation reaction will take place with addition of nanofluid in the methyl ester (Selim, Elfeky 2001). Performance characteristics of methyl ester are improved due to its natural increase in density impulse of nanofluid when exposed to higher temperature in combustion chamber. Radiative heat transfer and mass diffusivity of methyl ester is improved by adding nanofluid to biodiesel (De Luca et al. 2005; Galfetti et al. 2007). Performance parameters of diesel engine fuelled with biodiesel is considerably increased with addition of nanofluid as it has high ratio of surface area to volume (Prasher et al. 2006). It is reported that the ignition probability of methyl ester is improved by incorporating nanofluid which results in increase in efficiency and reduction in $\mathrm{NO}_{\mathrm{X}}$ emissions (Krishnamurthy et al. 2006).

In recent times, adding nano particles to liquid fuel is subjected to a lot of investigation. Arul Mozhi Selvan et al. (2014) studied the impact of cerium oxide nano particles of size $32 \mathrm{~nm}$ with a dosing level of $25 \mathrm{ppm}$ using diesterol in diesel engine. They found a significant reduction in $\mathrm{NO}_{\mathrm{x}}$ emissions. Shafii et al. (2011) investigated the effect of water based ferrofluid with a size of $10 \mathrm{~nm}$ and a concentration of

Corresponding author: Yuvarajan D

E-mail: dyuvarajan7@gmail.com 
$0 \%, 0.4 \%$, and $0.8 \%$ by volume in diesel fuel to views its effects on performance and emissions characteristics. It was found that the magnetic particles improves the combustion characteristics and reduce NOX emissions. Further, magnetic nano particles increase in chaotic movements and reducing in settling velocity of the particles which aids combustions. However, the impact on addition of ferrofluid to rice bran oil methyl ester has never been experimented. The present experimental study is aimed to examine the effect of ferrofluid on the various properties of methyl esters of rice bran oil and also its influence on performance and emissions characteristics. Experiments were carried out with RBOME and RBOMEF and are compared with petroleum diesel. RBOMEF was prepared comprising $98.5 \%$ biodiesel (Rice bran oil methyl ester), 1.3\% magnetite based ferrofluid and $0.2 \%$ surfactant by volume was used in a CI engine.

\section{Experimental material \& methods}

\subsection{Materials and reagents}

\subsubsection{Rice bran oil}

Rice bran oil is best suitable for high-temperature cooking methods such as stir frying and deep frying. It is accepted as cooking oil in several Asian countries. It has a low-cost feed stock with high value added by- products. In addition, the chemical properties of rice bran are closer to that of petroleum diesel. The properties of transesterifed methyl esters of rice bran oil fall well within the acceptable limit of ASTM standards. Rice bran is obtained as a by-product during polishing of rice from its kernel. Rice bran is dried to remove the water present in it. It is then fed to oil extractor which extracts oil by crushing. The oil obtained is classified as defatted and crude rice bran oil. Defatted rice bran oil with $16-20 \%$ of protein content is used for edible purpose. Crude rice bran oil with 23-24\% free fatty acid is used as the main source of biodiesel production process. Crude rice bran oil is converted into its methyl esters of rice bran oil by conventional transesterification process. The present work utilized refined Rice bran oil. The alcohol used in this work was methanol and $\mathrm{KOH}$ was used as catalyst for transesterifications.

\subsubsection{Ferrofluid}

Ferrofluid $\left(\mathrm{Fe}_{3} \mathrm{O}_{4}\right)$ is prepared using the following Eq. (1).

$$
\mathrm{FeCl}_{2}+2 \mathrm{FeCl}_{3}+8 \mathrm{NH}_{3}+4 \mathrm{H}_{2} \mathrm{O} \rightarrow \mathrm{Fe}_{3} \mathrm{O}_{4}+8 \mathrm{NH}_{4} \mathrm{Cl}
$$

Diameter of ferrofluid was in the order of $10 \mathrm{~nm}$ (Berger et al. 1999). Aqueous tri methyl ammonium hydroxide $((\mathrm{CH} 3) 3 \mathrm{NOH})$ solution is used as a surfactant to improve the bonding between ferrofluid to methyl ester. The most significant reason for using ferrofluid is that the magnetic nano particles can be collected from exhaust using magnetic billets. Furthermore, it can be easily diluted to biodiesel and as a result it can collect the benefits of water- biodiesel emulsions.

\subsection{Apparatus \& procedure}

\subsubsection{Base fuel preparation procedure}

Batch transesterification process is followed during conventional transesterification. Molar ratio of vegetable oil and alcohol is 5.9:1. $0.51 \%$ of catalysts (wt/wt) to rice bran oil were used. Temperature is maintained at $60{ }^{\circ} \mathrm{C}$ during transesterification process. Vegetable oil, methanol and catalysts are then mixed and stirred at $280 \mathrm{rpm}$ for 75 minutes. Further, the mixture is then allowed to cool. The top layer from the mixture is separated, washed and dried for further investigation. The ester obtained by conventional transesterification is used as a base fuel. Table 1 shows the fatty acids compositions of rice bran oil using Gas-liquid chromatography technique.

Table 1. Fatty acids compositions of rice bran oil

\begin{tabular}{cc}
\hline Fatty acids & Percentage \\
\hline Myristic acid & $0.9 \%$ \\
Palmitic acid & $21.5 \%$ \\
Stearic acid & $2.6 \%$ \\
Oleic acid & $37.7 \%$ \\
Linoleic acid & $35 \%$ \\
$\alpha$-Linolenic acid & $2.3 \%$ \\
\hline
\end{tabular}

\subsubsection{Modified base fuel preparations procedure (RBOMEF)}

$0.3 \%$ of aqueous tri methyl ammonium hydroxide and $1 \%$ of magnetite by volume is used in the study. Surfactant, magnetite and methyl esters of rice bran oil are mixed using ultrasonic agitator. Stability test were performed to view its phase change quality. Test results in homogeneity of magnetite in methyl esters of rice bran oil and found stable. The ester achieved by adding magnetite is referred as RBOMEF.

\subsection{Base and modified fuel properties}

Fuel properties of methyl esters and Diesel are shown in Table 2. There is a significant change in all the properties with addition of ferrofluid. $3.15 \%$ enhancement in Kinematic viscosity is observed by adding magnetite to methyl esters of rice bran oil. This is caused by increase in resistance among fuel layer. $2{ }^{\circ} \mathrm{C}$ increase in flash point is observed by adding magnetite to methyl esters of rice bran oil. Higher flash point is beneficial for safety measures. $0.02 \%$ increase in water content was found by adding magnetite to methyl esters of rice bran oil. This is due to presence of water content in ferrofluid. Higher water content will reduce the $\mathrm{NO}_{\mathrm{X}}$ emissions. Other property such 
as, density and calorific value of RBOMEF is enhanced by $2.96 \%$ and $2.61 \%$ respectively. This is due to positive effects of ferrofluid.

Table 2. Properties of test fuels

\begin{tabular}{lccc}
\hline \multicolumn{1}{c}{ Properties } & RBOMEF & RBOME & Diesel \\
\hline Kinematic Viscosity [cst] & 6.56 & 6.31 & 4.2 \\
Flash point $\left[{ }^{\circ} \mathrm{C}\right]$ & 143 & 137 & 50 \\
Water content [\%] & 0.152 & 0.131 & $\mathrm{Nil}$ \\
Density [gm/cc] & 0.911 & 0.881 & 0.821 \\
Calorific Value [kJ/kg] & 39243 & 38223 & 42957 \\
Cetane Index & 54 & 52 & 45 \\
\hline
\end{tabular}

\subsection{Experimental set-up \& testing procedure}

Air cooled compression ignition engine is used for experimentation. Technical specification of engine is illustrated in Table 3. Engine exhaust pipe is linked to AVL444 di gas analyzer having a maximum response time of $8 \mathrm{sec}$ for monitoring the engine emissions. The probe that is used to the exhaust gas analyzer was placed inside the exhaust pipe in which emissions such as $\mathrm{HC}, \mathrm{CO}$ and NOx are measured. Exhaust gas temperature was measured using K-type thermocouple made of Chrome-alumel with digital indicating unit. U-tube manometer having one end connected to tank and other end left free to ambient is used to measure the air flow rate. Pressure inside the cylinder was measured with the help of an AVL pressure transducer with sensitivity of $16.04 \mathrm{pc} / \mathrm{bar}$, linearity of $< \pm 0.3 \%$ and the crank angle were inferred using a TDC encoder. Both the pressure transducer and TDC encoder were linked to a computer for monitoring and recording the combustion parameters through AVL 617 indimeter of software version V2.00. Details of gas analyzer are shown in Table 4. Figure 1 shows the layout of engine and instrumentation set up.

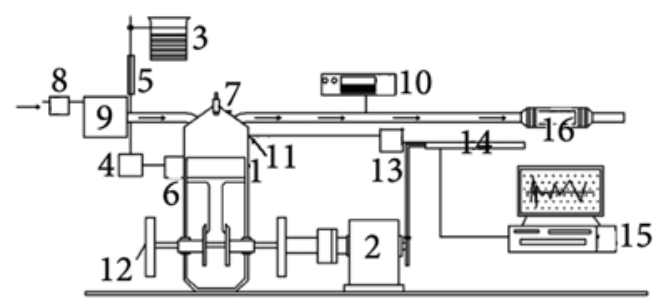

\footnotetext{
1. Kirloskar TV1 engine

2. Eddy current dynamometer

3. Fuel tank

4. Fuel filter

5. Fuel measurement setup

6. Fuel pump

7. Fuel injector

8. Air filter
}

9. Air stabilizing tank

10. Smoke meter and flue gas analyzer

11. Pressure transducer

12. TDC encoder

13. Charge amplifier

14. Indimeter

15. Monitor

16. Exhaust silencer
Table 3. Specifications of the engine

\begin{tabular}{lc}
\hline \multicolumn{1}{c}{ Make } & Kirloskar \\
\hline Stroke & 4 \\
Number of Cylinders & 1 \\
Power rated & $4.45 \mathrm{~kW}$ \\
Speed rated & $1500 \mathrm{rpm}$ \\
Bore diameter(D) & $87.5 \mathrm{~mm}$ \\
Stroke length(L) & $110 \mathrm{~mm}$ \\
Compression ratio & $17.5: 1$ \\
\hline
\end{tabular}

Table 4. Details of gas analyzer

\begin{tabular}{cccc}
\hline Parameters & Make & Accuracy & $\begin{array}{c}\text { Relative } \\
\text { Uncertainty }\end{array}$ \\
\hline CO & & 0.01 & $\pm 3 \%$ \\
HC & AVL gas & $\pm 10 \mathrm{ppm}$ & $\pm 2 \%$ \\
NOx & analyzer & $\pm 10 \mathrm{ppm}$ & $\pm 2.5 \%$ \\
\hline
\end{tabular}

\subsection{Error analysis}

The error analysis for $\mathrm{HC}$ emission are calculated using the Equation (2)

$$
\sigma_{H C}=\left[\frac{\sum_{i=1}^{n}\left((H C)_{i}-(\overline{H C})\right)^{2}}{n-1}\right]^{\frac{1}{2}} .
$$

The uncertainty in $\Delta(H C)$ in hydrocarbons is calculated by Equation (3)

$$
\frac{\sigma_{H C}}{\sqrt{n}},
$$

where $\underline{n}=$ number of $\mathrm{HC}$ measurements,

$\overline{\mathrm{HC}}=$ mean value of $\mathrm{HC}$ measurements,

$\sigma_{H C}=$ unbiased standard deviation for HC measurements.

By adapting the above equation, the error analysis of other emissions such as $\mathrm{CO}$, NOx and smoke were analysed.

\section{Results and discussion}

\subsection{Effect of magnetite on emission parameters}

\subsubsection{Hydrocarbon emissions}

Figure 2 shows the change in $\mathrm{HC}$ emissions for all the test fuels with respect to load. Average HC emission from diesel, RBOME and RBOMEF is $46.5 \mathrm{ppm}, 44.7$ ppm and $38.0 \mathrm{ppm}$ at all loads respectively. Significant reduction in $\mathrm{HC}$ emissions were observed for RBOME and RBOMEF when compared to diesel. RBOME and RBOMEF have inbuilt oxygen content which helps in improved combustion and lesser $\mathrm{HC}$ emissions. $\mathrm{Pu}-$ han et al. (2005) found that reduction in HC emission

Fig. 1. Layout of experimental setup 
was about $63 \%$ for methyl ester compared with Diesel. Alam et al. (2004) observed significance reduction in HC emission for methyl ester comparing diesel citing ample availability of oxygen as the reason. By adding magnetite to RBOME, 9.1\% reductions in $\mathrm{HC}$ emissions were found. Activation temperature of carbon combustion is lowered by adding magnetite which performs as oxidation catalysts. Similar trend was mentioned on the experimental work by (Sajith et al. 2010; Kannan et al. 2011).

\subsubsection{Carbon monoxide emissions}

Figure 3 shows the change in $\mathrm{CO}$ emissions for all the test fuels with respect to load. An average $\mathrm{CO}$ emission from diesel, RBOME and RBOMEF is $0.07425,0.06875$ and $0.066 \%$ volume correspondingly. $\mathrm{CO}$ emissions for RBOME and RBOMEF are significantly lower than diesel. This is due to enhanced oxidation reaction during combustion owing to higher content of oxygen of RBOME and RBOMEF. Puhan et al. (2005) found 70\% reduction in $\mathrm{CO}$ emissions when fuelled with Maua oil methyl ester. For all the fuels, $\mathrm{CO}$ emission increases with increase in load. This is due necessity of rich mixture with increase in load to sustain steady power output. Ulusoy et al. (2009) found increase in CO emission with increase in load citing decrease in air fuel ratio at higher loads as the cause. By adding magnetite to RBOME, $6.34 \%$ reductions in HC emissions were observed. This is due to increased surface area to volume ratio of magnetite which improves the mixing rate of air and fuel as cited by Lenin et al. (2013). Further, RBOMEF has a lesser delay period due to the presence of magnetite which results in complete oxidation. The obtained result is justified with of similar work done by Selvan et al. (2004), Kim, Choi (2010).

\subsubsection{Nitrogen oxide emissions}

Figure 4 shows the change in $\mathrm{NO}_{\mathrm{x}}$ emissions for all the test fuels with respect to load. Average $\mathrm{NO}_{\mathrm{X}}$ emission from diesel, RBOME and RBOMEF is 149,175 and $197 \mathrm{ppm}$ correspondingly. NOX emissions for RBOME and RBOMEF are higher than diesel by $23.5 \%$ and $18.74 \%$. Since the peak pressure of RBOME and RBOMEF is higher than diesel, higher $\mathrm{NO}_{\mathrm{x}}$ emissions are obvious. By adding magnetite to RBOME, 8.49\% reductions in $\mathrm{NO}_{\mathrm{x}}$ emissions were observed. The possible reason is due to shorter ignition delay period for RBOMEF. By adding magnetite to methyl ester of rice bran oil the combustion rate is improved. Further, the water present in magnetite reduces the peak combustion temperature thereby reducing $\mathrm{NO}_{\mathrm{x}}$ emissions for RBOMEF. Similar results were citied on the experimental work done by Shafii et al. (2011).

\subsection{Effect of magnetite on performance parameters}

\subsubsection{Brake thermal efficiency}

Figure 5 shows Brake thermal efficiency of RBOME, RBOMEF with respect to load. It is inferred that BTE for diesel is higher than RBOME and RBOMEF. This is attributed to higher viscosity of methyl esters when compared to diesel. It was reported from the past information that BTE decreases with the increase in cottonseed oil methyl ester in the blends comparing diesel due to its higher viscosity and lower heating value (Aydin, Bayindir 2010). Moreover the calorific value of diesel is higher as compared to RBOME and RBOMEF. Higher calorific value leads to lesser requirement of fuel for delivering any given rated power. BTE for RBOMEF is higher than RBOME by $4.27 \%$. Since the density of RBOMEF is $2.97 \%$ higher than

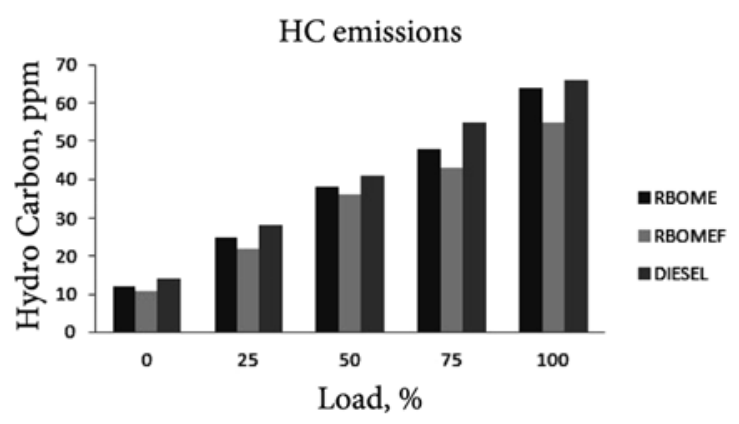

Fig. 2. Hydro carbon emissions with respect to load

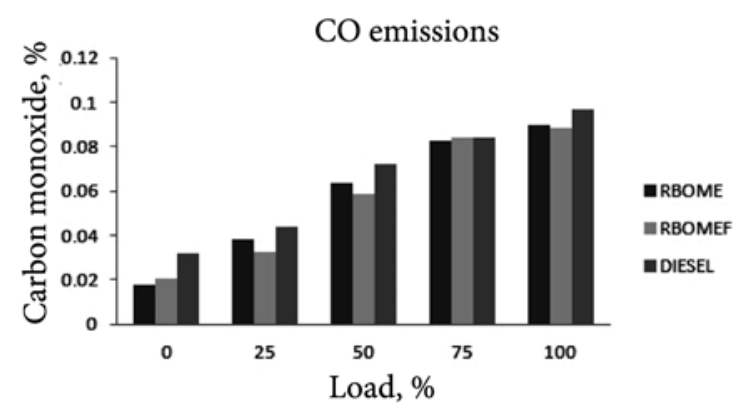

Fig. 3. Carbon monoxide emission with respect to load



Fig. 4. NOx emission with respect to load 
RBOME the mixture momentum and penetration depth in cylinder is controlled and result in shorter ignition delay and enhanced combustion. Furthermore, the fuel with higher density as in the case of RBOMEF restrains spray tip penetration, ensuing that the air fuel mixture is only created at the core region of the combustion chamber owing to improved combustion (Raheman, Phadatare 2004). The other reason is due to higher availability of oxygen which enhances air fuel mixing and increase efficiency Shafii et al. (2011)

\subsubsection{Specific fuel consumption}

SFC of RBOME, RBOMEF is shown in Figure 6. SFC for diesel is least during the trail. This is because of higher calorific value of diesel. Further, addition of ferrofluid decreases SFC. Average BSFC for RBOMEF is lesser than

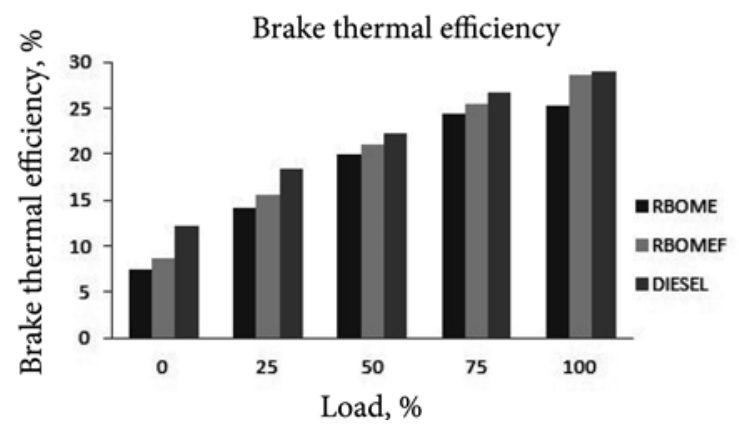

Fig. 5. Brake thermal efficiency with respect to load

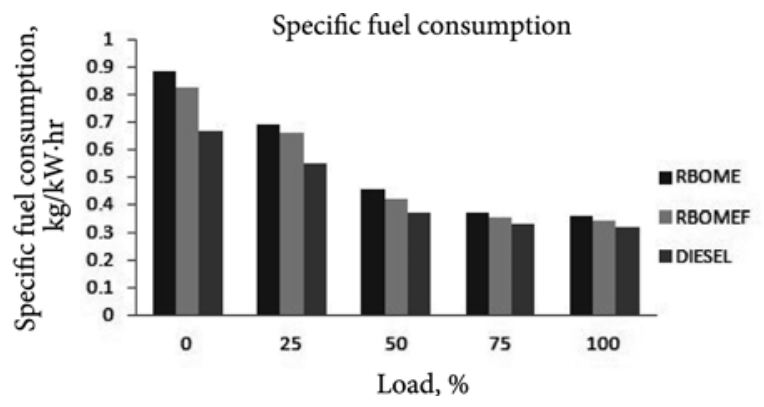

Fig. 6. Specific fuel consumption with respect to load

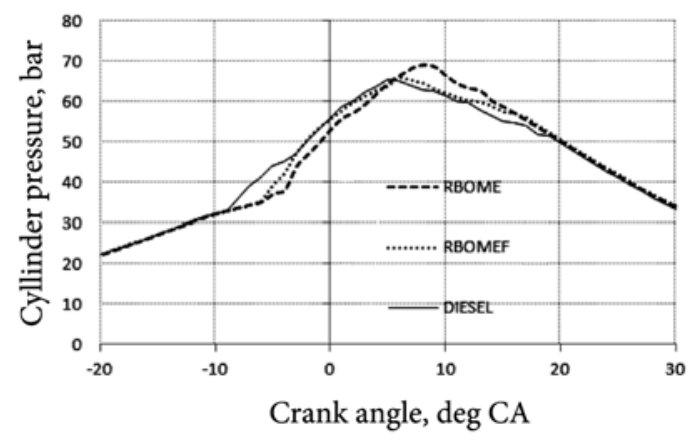

Fig. 7. Variation of pressure with crank angle
RBOME by $5.17 \%$.This is due to positive effect of ferrofluid which reduces ignition delay thereby reducing fuel consumption. The other reason is due to surplus availability of oxygen in RBOMEF which promotes improved combustion and lesser consumption of fuel. Furthermore, nanosized particles can be dispersed into high-temperature zones for direct oxidation reaction leading shorter delay period thereby resulting in lesser consumption of fuel (Shafii et al. 2011).

\subsubsection{Pressure vs crank angle}

Figure 7 shows the variation in pressure with crank angle for RBOME, RBOMEF and Diesel at full load conditions. Peak pressure of RBOME is higher than RBOMEF and Diesel by $4.18 \%$ and $5.34 \%$.Since the viscosity of RBOME is higher by $5.94 \%$ comparing RBOMEF atomization and mixing of fuel with air is not in uniform rate causing longer breakup length, lower dispersion rate and increased ignition delay. Due to longer delay period more measure of fuel is accumulated causing rapid increase in peak pressure. Similar results were cited on the experimental work by (Buyukkaya 2010).

It is also inferred that the peak pressure of Diesel is lesser than RBOME and RBOMEF. This is due to reduced fuel consumption of diesel in comparison with RBOME and RBOMESUM ensuring improved atomization and better combustion which result in shorter ignition delay and lower peak pressure. It is also inferred that by addition of ferrofluid the peak cylinder pressure is reduced by $3.35 \%$. This is due to shorter delay period and improved ignition properties of nanoparticles which initiate the early combustion when compared to RBOME as cited by (Basha, Anand 2011). The other reason is as a result of higher cetane number of RBOMEF which initiates faster evaporation and improved combustion leading to shorter ignition delay. It is also observed that the occurrence of peak pressure is advanced with addition of ferrofluid due to shorter ignition delay. This is due to surplus oxygen in ferrofluid which promotes improved combustion. This is in agreement with similar work done by (Buyukkaya 2010).

\section{Conclusion}

The following conclusions were drawn by adding magnetite to methyl esters of rice bran oil in a constant speed diesel engine.

(1) $6.34 \%$ of CO emission is reduced by adding ferrofluid to methyl ester due to magnetite which undergoes catalytic oxidation reaction and causing complete oxidation during combustion.

(2) $9.1 \%$ of $\mathrm{HC}$ emission is reduced with addition of magnetite. HC oxidation reaction is improved due to the presence of ferrofluid which acts as an oxidation catalyst and lowers the carbon combustion activation temperature. 
(3) $8.49 \%$ of NOX emission is achieved by doping magnetite to methyl ester. This is achieved as a result of latent heat of evaporation of water present in ferrofluid.

(4) Engine performance is enhanced by $4.27 \%$ along with $5.17 \%$ reduction in BSFC. This is due to higher availability of oxygen which enhances air fuel mixing during combustion. Ferro fluid also possesses desirable combustion characteristics such as high heats of combustion and fast energy release rates.

Adding magnetite to methyl esters of rice bran oil is promising technique to offset the drawbacks associated with it.

\section{References}

Alam, M.; Song, J.; Acharya, R.; Boehman, A.; Miller, K. 2004. Combustion and emissions performance of low sulfur, ultra low sulfur and biodiesel blends in a DI diesel engine, SAE Technical Paper Series.

http://dx.doi.org/10.4271/2004-01-3024

Arul Mozhi Selvan, V.; Anand, R. B.; Udayakumar, M. 2014. Effect of cerium oxide nanoparticles and carbon nanotubes as fuel-borne additives in Diesterol blends on the performance, combustion and emission characteristics of a variable compression ratio engine, Fuel 130: 160-167.

http://dx.doi.org/10.1016/j.fuel.2014.04.034

Aydin, H.; Bayindir, H. 2010. Performance and emission analysis of cottonseed oil methyl ester in a diesel engine, Renewable Energy 35(3): 588-592.

http://dx.doi.org/10.1016/j.renene.2009.08.009

Basha, J. S.; Anand, R. B. 2011. An experimental study in a CI engine using nanoadditive blended water-diesel emulsion fuel, International Journal of Green Energy 8(3): 332-348. http://dx.doi.org/10.1080/15435075.2011.557844

Berger, P.; Adelman, N. B.; Beckman, K. J.; Campbell, D. J.; Ellis, A. B.; Lisensky, G. C. 1999. Preparation and properties of an aqueous ferrofluid, Journal of Chemical Education 76(7): 943-948. http://dx.doi.org/10.1021/ed076p943

Buyukkaya, E. 2010. Effects of biodiesel on a DI diesel engine performance, emission and combustion characteristics, Fuel 89(10): 3099-3105.

http://dx.doi.org/10.1016/j.fuel.2010.05.034

Choi, S. H.; Oh, Y. 2006. The emission effects by the use of biodiesel fuel, International Journal of Modern Physics B 20: 4481-4486. http://dx.doi.org/10.1142/s0217979206041550

De Luca, L. T.; Galfetti, L.; Severini, F. 2005. Burning of nanoaluminized composite rocket propellants, Combustion, $E x$ plosion and Shock Waves 41(6): 680-692. http://dx.doi.org/10.1007/s10573-005-0080-5

Galfetti, L.; DeLuca, L. T.; Severini, F.; Meda, L.; Marra, G. 2007. Pre and post- burning analysis of nano-aluminized solid rocket propellants, Aerospace Science and Technology 11(1): 26-32. http://dx.doi.org/10.1016/j.ast.2006.08.005

Jung, H.; Kittelson, D. B.; Zachariah, M. R. 2005. The influence of a cerium additive on ultrafine diesel particulate emissions and kinetics of oxidation, Combustion and Flame 142(3): 276-278.

http://dx.doi.org/10.1016/j.combustflame.2004.11.015
Kannan, G. R.; Karvembu, R.; Anand, R. 2011. Effect of metal based additive on performance emission and combustion characteristics of diesel engine fuelled with biodiesel, Applied energy 88(11): 3694-3703.

http://dx.doi.org/10.1016/j.apenergy.2011.04.043

Karabektas, M. 2009. The effects of turbocharger on the performance and exhaust emissions of a diesel engine fuelled with biodiesel, Renewable Energy 34(4): 989-993. http://dx.doi.org/10.1016/j.renene.2008.08.010

Kim, H.; Choi, B. 2010. 2010. The effect of biodiesel and bioethanol blended diesel fuel on nanoparticles and exhaust emissions from CRDI diesel engine, Renewable Energy 35(1): 157-163. http://dx.doi.org/10.1016/j.renene.2009.04.008

Krishnamurthy, S.; Bhattacharya, P.; Phelan, P. E.; Prasher, R. S. 2006. Enhanced mass transport in nanofluids, Nano Letters 6(3): 419-423. http://dx.doi.org/10.1021/nl0522532

Lenin, M. A.; Swaminathan, M. R.; Kumaresan, G. 2013. Performance and emission characteristics of a DI diesel engine with a nanofuel additive, Fuel 109: 362-365. http://dx.doi.org/10.1016/j.fuel.2013.03.042

Prasher, R.; Bhattacharya, P.; Phelan, P. E. 2006. Brownianmotion-based convective-conductive model for the effective thermal conductivity of nanofluids, Journal of Heat Transfer 128(6): 588-595. http://dx.doi.org/10.1115/1.2188509

Puhan, S.; Vedaraman, N.; Sankaranarayanan, G.; Ram, B. V. B. 2005. Performance and emission study of Maua oil methyl ester in a 4-stroke natural aspirated direct injection diesel engine, Renewable Energy 30(8): 1269-1278.

http://dx.doi.org/10.1016/j.renene.2004.09.010

Raheman, H.; Phadatare, A. G. 2004. Diesel engine emissions and performance from blends of karanja methyl ester and diesel, Biomass and Bioenergy 27(4): 393-397. http://dx.doi.org/10.1016/j.biombioe.2004.03.002

Ramadhas, A. S.; Muraleedharan, C.; Jayaraj, S. 2005. Performance, emission evaluation of a diesel engine fuelled with methyl esters of rubber seed oil, Renewable Energy 30(12): 1789-1800. http://dx.doi.org/10.1016/j.renene.2005.01.009

Ryu, K. 2010. The characteristics of performance and exhaust emissions of a diesel engine using a biodiesel with antioxidants, Bioresource Technology 101(1): S78-82. http://dx.doi.org/10.1016/j.biortech.2009.05.034

Sajith, V.; Sobhan, C. B.; Peterson, G. P. 2010. Experimental investigations on the effects of cerium oxide nanoparticle fuel additives on biodiesel, Advances in Mechanical Engineering 2(0): 581407. http://dx.doi.org/10.1155/2010/581407

Selim, M. Y. E.; Elfeky, S. M. S. 2001. Effects of diesel/water emulsion on heat flow and thermal loading in a pre combustion chamber diesel engine, Applied Thermal Engineering 21(15): 1565-1582. http://dx.doi.org/10.1016/s1359-4311(01)00019-9

Shafii, M. B.; Daneshvar, F.; Jahani, N.; Mobini, K. 2011. Effect of ferrofluid on the performance and emission patterns of a four stroke diesel engine, Advances in Mechanical Engineering 3(0): 529049. http://dx.doi.org/10.1155/2011/529049

Ulusoy, Y.; Arslan, R.; Kaplan, C. 2009. Emission characteristics of sunflower oil methyl ester, Energy Sources, Part A Recovery, Utilization, and Environmental Effects 31(11): 906-910. http://dx.doi.org/10.1080/15567030802087528 


\section{APPENDIX}

\section{Sample calculation to find Uncertainty for $\mathrm{HC}$ emission}

The five measurements of HC for RBOME are 25 ppm, 38 ppm, 48 ppm and 64 ppm.

The standard deviation for the measurements is

$$
\sigma_{H C}=2.75 \text {. }
$$

The uncertainty in $\mathrm{HC}$ is given by

$$
\Delta(\mathrm{HC})=\frac{2.75}{\sqrt{ } 5}=1.223 \mathrm{ppm} .
$$

Relative uncertainty $=\frac{1.223}{64} \times 100 \%=1.91 \approx 2 \%$.

In the same procedure, uncertainty of $\mathrm{NO}_{\mathrm{x}}$ and $\mathrm{CO}$ are calculated.

YUVARAJAN D received his B.E degree in Mechanical engineering from Anna University, India in 2006 and M.E degree in Energy Engineering from College of Engineering, Anna University, India in 2009. He is currently an assistant professor in Jeppiaar Institute of Technology, India and correspondingly perusing his Ph.D. degree in Anna University, India. His research area includes performance, combustion and emissions characteristics in $\mathrm{CI}$ engines and fuel additives.

VENKATA RAMANAN M received his B.E degree in Mechanical engineering from University of Madras, India in 1998 and M. Tech degree in Energy conservation and Management from School of Energy, Tiruchirappalli, India in 2000. He received his Ph.D. in Biomass Gasification at Anna University, India in 2008. He is currently an Assistant Professor (Senior Grade) in Department of Mechanical Engineering, Anna University, India. He is an energy auditor and has consulted many industrial houses for energy conservation studies. His research area includes IC engines, gasification and energy optimization in process utilities. He has published more than 30 international journal papers on his area of research. 